[0212-7199 (2006) 23: 9; pp 446-448] ANALES DE MEDICINA INTERNA Copyright (C) 2006 ARAN EDICIONES, S.L.

AN. MED INTERna (Madrid) Vol. 23, N. ${ }^{\circ}$ 9, pp. 446-448, 2006

\title{
Tratamiento con vitamina D en la infancia: discusión de la evidencia
}

\author{
I. VILLAMIL CAJOTO, M. J. VILLACIÁN VICEDO', D. ARAÚJO VILAR² \\ Servicio de Medicina Interna. Hospital Clínico Universitario. Santiago de Compostela. \\ ${ }^{1}$ Pediatría. CS Palas de Rei. Lugo. ${ }^{2}$ Unidad de Enfermedades Tiroideas y Metabólicas. \\ Departamento de Medicina. Universidad de Santiago de Compostela
}

\author{
VITAMIN D TREATMENT IN CHILDHOOD AN EVIDENCE BASES \\ DISCUSION
}

\section{RESUMEN}

El tratamiento con vitamina $\mathrm{D}$ en el primer año de vida está siendo recomendado desde hace años. Las indicaciones para el mismo están basadas en datos no suficientemente contrastados para realizarse en la población general. La evidencia de que la exposición solar es suficiente en la gran mayoría de los niños menores de 1 año para obtener niveles óptimos de vitamina D debe tenerse en cuenta. Todavía no han sido realizados estudios que demuestren la dosis óptima en esta etapa vital. Nuestra revisión sugiere que la exposición solar en España podría ser suficiente.

PALABRAS CLAVE: Vitamina D. Exposición solar. Rayos ultravioletas. Raquitismo. Pigmentación de la piel.

\section{ABSTRACT}

Vitamin D treatment during childhood it's been recommended in those younger than one. Evidence is not available to recommend this treatment in general population. Solar exposure is enough in most infants younger than 1 year, and this should be taken into account. Data showing optimal doses at this stage is not available to date. Our review suggests, solar exposure in Spain could show sufficient.

KEY WORDS: Vitamin D. Sunlight. Ultraviolet rays. Rickets. Skin pigmentation.

Villamil Cajoto I, Villacián Vicedo MJ, Araújo Vilar D. Tratamiento con vitamina D en la infancia: discusión de la evidencia. An Med Interna (Madrid) 2006; 23: 446-448.

\section{INTRODUCCIÓN}

La vitamina D se sintetiza en la piel a partir del colesterol con la exposición a la luz ultravioleta B (UVB). Después, es hidroxilada en el hígado (25-0H vitamina D o calcidiol) y posteriormente en los riñones $(1,25-0 \mathrm{H} 2$ vitamina $\mathrm{D}$ o calcitriol). La carencia de esta vitamina, provoca alteraciones óseas que conducen al raquitismo. La vitamina $\mathrm{D}$ de la dieta se absorbe en el intestino delgado como vitamina liposoluble incorporada en los quilomicrones, se deposita en el hígado y junto con la vitamina D3 sintetizada endógenamente, es metabolizada $(1,2)$.

Los lactantes alimentados con leche materna tienen varias fuentes de vitamina $\mathrm{D}$, entre ellas el paso transplacentario (aunque se sabe poco sobre el almacenamiento de vitamina D por el feto, se considera que las reservas se agotan hacia los 2 meses de vida) (3), la síntesis endógena por exposición a la luz solar y la aportada en la leche materna que se sabe además que es mejor absorbida que la que aportan las fórmulas maternizadas.
La exposición solar de cuerpo entero total consigue niveles equivalentes a una ingesta oral de vitamina D3 (colecalciferol) de 250 microg (10.000 UI) (4) El contenido de vitamina $\mathrm{D}$ de la leche humana es de alrededor de $20 \mathrm{UI} / \mathrm{L}$, en su mayor parte en forma de $25-\mathrm{OH}$ vitamina D (Tabla I), aunque existe variación en función de la exposición solar de la madre. Así, se ha demostrado que con una dosis de 1,5 MED de exposición corporal total a luz ultravioleta (UVB), (aproximadamente 90 segundos de radiación en población de raza blanca), aumenta 10 veces las cifras de vitamina D en la leche (5), siendo inferior el aumento en las madres de raza negra, en quienes la pigmentación cutánea disminuye la absorción de luz UVB (4). En cuanto a la producción cutánea, se ha demostrado que una exposición de entre 50 minutos y 2 horas a la luz solar a la semana en lactantes de raza blanca vestidos por completo salvo en cabeza y manos en Cincinnati, Ohio (EE.UU.) (latitud 39 grados Norte) mantiene cifras séricas de $25-\mathrm{OH}$ vitamina D de $11 \mathrm{ng} / \mathrm{ml}$ (7). En un estudio en lactantes de raza blanca en Madison, Wiconsin (EE.UU.) (latitud 43

Trabajo aceptado: 28 de agosto de 2006

Correspondencia: Iago Villamil Cajoto. Servicio de Medicina Interna. Hospital Clínico Universitario de Santiago de Compostela. Choupana, s/n. 15706 Santiago de Compostela (A Coruña).e-mail: iago.villamil.cajoto@sergas.es 
TABLA I

\begin{tabular}{|c|c|c|c|}
\hline \multicolumn{4}{|c|}{$\begin{array}{c}\text { CONTENIDO DE ALGUNAS VITAMINAS EN LA LECHE } \\
\text { HUMANA MADURA, LECHE DE VACA Y LECHES } \\
\text { MATERNIZADAS (EE.UU.) (21) }\end{array}$} \\
\hline Vitamina /L & Leche humana & Leche de vaca & Leche maternizada \\
\hline$A_{,}(U I)$ & 2.230 & 1.000 & 2.225 \\
\hline$D_{1}(\mathrm{UI})$ & $<20$ & 24 & 400 \\
\hline K, (microg) & 2,1 & 4,9 & 55 \\
\hline
\end{tabular}

grados Norte), durante los primeros seis meses de vida se observó que los lactantes alimentados de modo exclusivo al pecho materno no requirieron complementos de vitamina $\mathrm{D}$ para conservar las concentraciones de 25-OH vitamina D (13$25 \mathrm{ng} / \mathrm{ml}$ ) (8). Parece por tanto existir suficiente evidencia científica que avala que la máxima y más importante producción de vitamina $\mathrm{D}$ en esta edad es derivada de la síntesis cutánea y se recomienda en general exposiciones de 15 minutos en cara y manos diariamente, para conseguir niveles óptimos.

Desde el punto de vista geográfico, la península ibérica se encuentra entre una latitud 43 grados norte (exactamente $43^{\circ}$ $47^{\prime} 24^{\prime \prime}$ Norte, en Estaca de Bares) y 36 grados norte (en concreto $36^{\circ} 00^{\prime} 33^{\prime \prime}$ Norte, en Tarifa). La Comunidad Autónoma de Canarias, se encuentra a una latitud entre $27^{\circ}$ y $29^{\circ}$ Norte, según las islas del archipiélago. Teniendo en cuenta lo anterior, las necesidades de radiación para la producción de suficiente vitamina D estarían garantizadas con la exposición solar habitual, al menos en los meses no invernales.

\section{RAQUITISMO}

La necesidad de suplementación de vitamina durante la infancia parece haberse aceptado universalmente, aunque las tasas de raquitismo se mantienen en los países en desarrollo (9). En la patogénesis del raquitismo parece que hay otros factores que permitirían explicar por qué en poblaciones con suficiente exposición solar la prevalencia de esta enfermedad se mantiene alta (10). Así factores predisponentes, de tipo genético en el metabolismo de la vitamina $\mathrm{D}$, de estilo de vida, culturales (algunas sociedades presentan menor exposición solar por el estilo de la indumentaria), y nutricionales (como el consumo de ciertos alimentos ricos en fitatos que interfieren en la absorción del calcio) (11-13) y especialmente el propio déficit de calcio, parecen ser uno de los principales factores que contribuyen en el raquitismo en la población africana (14). En este contexto, podrían explicarse recientes comunicaciones sobre incremento de raquitismo en población inmigrante en países desarrollados (15). Los datos de raquitismo actuales en países desarrollados son significativos, aunque la lectura de las comunicaciones que los acreditan tiene varias interpretaciones. Así, parece existir un incremento, lo cual no deja de ser preocupante, pero el análisis de los pacientes afectados es revelador. Por ejemplo, en EEUU de los 96 niños con raquitismo descritos en los últimos años, 90 eran afroamericanos (y en estos se ha demostrado que la síntesis solar puede ser insuficiente), y los otros 6 pacientes eran de raza caucásica pero sus circunstancias eran peculiares: 1 niño había permanecido encerrado durante su infancia, en otro no se define la "dieta inusual" que se relaciona con la patología, otro no reci- bió ningún aporte de leche tras sólo dos meses de lactancia (16). Es decir, situaciones clínicas sociales y familiares muy particulares.

\section{LAS GUÍAS Y LA PRÁCTICA}

El aporte extra de vitamina D oral, se recomienda en las conclusiones de la Sociedad Europea de Endocrinología Pediátrica (16) y de de la Academia Americana de Pediatría (AAP) (17). Las recomendaciones de las Guías de Salud del Niño Sano en nuestro país adoptan estos dogmas, aunque es común en la práctica diaria el escepticismo ante estas recomendaciones. Sin embargo, todas las Comunidades Autónomas recomiendan el tratamiento con vitamina D oral (con diferentes dosis, pero ese sería motivo de otro comentario), en el primer año de vida. Desde nuestro punto de vista y según lo explicado, parece cuestionable la recomendación. Así, incluso si la exposición solar en las latitudes de nuestro país fuese insuficiente en los meses de invierno, se contempla la posibilidad de acumulación vitamina $\mathrm{D}$ (liposoluble) en la grasa corporal tras su producción suficiente durante los meses en los que la intensidad lumínica estuviera garantizada (la mayoría del año en nuestras latitudes), por lo que la recomendación sin más de aportes extras, parece cuestionable. Pero además, en el caso de la AAP se realiza en función de unas alarmas que no son estrictamente superponibles en nuestro país. Esto es, las recomendaciones de la AAP son universales y reconocen en su documento que la población de raza negra precisaría aportes extras de vitamina D que tal vez no sería imprescindibles en la población de raza blanca. Sobre estos últimos sin embargo, insisten en la recomendación por que sugieren, de forma enérgica a su vez, la protección solar (cremas con filtros de alto factor de protección) a todos los menores de1 año (18). Nuevamente aparecen dudas razonables para indicarse el tratamiento universal en nuestra población, que desde luego no está aplicando filtros solares de forma universal, aunque la Asociación Española de Pediatría lo comienza a recomendar.

No hay suficiente evidencia para incluir a la vitamina D en las recomendaciones de las Recommended Dietary Allowance (RDA) (16), salvo en el primer año de vida y esto se hace a partir de la recomendación de los años 40 del siglo 20, en que se indicaba que la dosis correcta para la prevención de raquitismo es una "cucharilla de té" $(5 \mathrm{ml})$ de aceite de pescado (19). No hay definiciones científicas más rigurosas, ni estudios exactos de la dosis óptima, hasta ahora y, lo que se ha hecho, es determinar la ingesta adecuada o nivel de ingesta suficiente para mantener niveles séricos "saludables" de calcitriol. La OMS define la unidad internacional de vitamina D3 como la actividad de 0,025 microg de la preparación internacional estándar de vitamina D3 cristalina, así la definición en términos molares de calcitriol coincide con la de la vitamina D3 "original" (16).

En EE.UU. desde los años 30, se realizan aportes de vitamina $\mathrm{D}$ en todas las leches comercializadas (para uso de adulto y en la infancia, además de las fórmulas artificiales maternizadas). En Europa no existe esta práctica, que por igual regla de tres se podría aplicar. De hecho, ¿por qué recomendar sólo en el primer año de vida los suplementos? No se ha podido determinar a ciencia cierta la recomendación del suplementos de vitamina $\mathrm{D}$ en exclusiva para el primer año de vida, y el déficit moderado de vitamina $\mathrm{D}$ en pacientes mayores de 1 año hace 
que éste sólo se manifieste como malabsorción indetectada de calcio o discreta elevación de hormona paratiroidea con rápida remodelación ósea, con consecuencias óseas metabólicas igualmente. Por tanto, en este grupo de edad de más de 1 año sí se individualiza el suplemento, pero no en pacientes menores a los que se recomienda sistemáticamente (16).

Está además descrito (quien ha usado el fármaco conoce las circunstancias), un uso de la vitamina $\mathrm{D}$ poco correcto, por problemas mecánicos en la administración del producto (12) y por la tendencia general a considerar las vitaminas como no peligrosas, por lo que la posibilidad de sobredosificación también está presente (20).

Por último, las implicaciones de la calidad del hueso en la edad adulta están relacionados también con las primeras etapas de la vida. Se sabe que a diferencia de la osteomalacia, en la que existe una mineralización escasa y volumen óseo normal, en la osteoporosis la mineralización es normal pero existe una reducción del volumen óseo, en especial de hueso trabecular. Deben conocerse las implicaciones del ciclo vital de la desmineralización ósea o de la osteopororis en la infancia sobre la densidad mineral ósea final. Un factor importante que evita el desarrollo de la osteoporosis menopáusica y en el adulto en general, es la masa ósea que existe en el adulto en el momento en que ésta comienza a disminuir (el pico máximo de masa ósea se obtiene alrededor de los 20 años). Por eso es importante el ejercicio en niños y adolescentes, evitar el alcohol y el tabaco y los refuerzos en el contenido de vitamina $\mathrm{D}$ en la dieta sin que existan evidencias definitivas de la necesidad de aporte extra si se aseguran las 400-800 UI diarias en la dieta (22).

\section{CONCLUSIONES}

En definitiva, la optimización de la salud ósea exige algo más que calcio y vitaminas (al menos orales). Aportamos las reflexiones anteriores para suscitar la controversia necesaria en una práctica que tal vez haya estado guiada por la inercia (desde la dosis de uso, que se basa en datos de 1940, no confirmados ni revisados, hasta la aplicación uniforme de guías de práctica clínica quizás no trasponibles en nuestro medio). Creemos que los suplementos con vitamina D oral están indicados en los casos en los que la exposición solar y los posibles déficit carenciales puedan comprometer el desarrollo óseo, también es posible su indicación en otros casos individuales como los grandes prematuros entre otros. Puede que la conclusión de que "al menos no hace mal" esté siendo el factor más importante en la indicación del tratamiento, y la evidencia de adecuación de la dosis y el tipo de pacientes que lo necesitarían requiere nuevas aproximaciones. Según esta línea de pensamiento, se podría deducir que, con la vitamina D oral, la exposición solar no sería necesaria (siguiendo estrictamente las recomendaciones de las guías de referencia), a riesgo de caer en una "sobredosificación”. Se precisan estudios más amplios para definir definitivamente la actitud correcta. En cualquier caso nos parece no ajustado a la evidencia científica disponible, la recomendación sin más de vitamina $\mathrm{D}$ oral sin individualizar la situación del lactante, la situación familiar y social, y sin evaluar las posibilidades de exposición solar controlada, entre otros factores.

\section{Bibliografía}

1. Reichel H, Koeffler HP, Norman AW. The role of the vitamin D endocrine system in health and disease. N Engl J Med 1989; 320: 980-91.

2. Brown AJ. Regulation of vitamin D action. Nephrol Dial Transplant 1999; 14: 11-16.

3. Hoogenboezen T, Degenhart HJ, De Muinch Keizer-Scharma SM, Bouillon R, Grose WF, Hackeng WH, Visser HK: Vitamin D metabolism in breast-fed infants and their mothers. Pediatr Res 1989; 25: 623628.

4. Stamp TC. Factors in human vitamin D nutrition and in the production and cure of classical rickets. Proc Nutr Soc 1975; 34: 119-30.

5. Creer FR, Hollis BW, Cripps DJ, Tsang RC. The effects of ultraviolet B light irradiation on the vitamin D content of human milk. J Pediatr 1984; 105: 431-433.

6. Specker BL, Tsang RC, Hollis BW: effect of race and diet on human milk vitamin D and 25-hidroxyvitamin D. Am J Dis Child 1985; 139: 1134-1137.

7. Specker BL, Tsang RC. Cyclical serum 25-hydroxyvitamin D paralleling sunshine exposure in exclusively breast-fed infants: mirror image in summer vs. winter J Pediatr 1987; 110: 744-747.

8. Greer FR, Marshall S. Bone Mineral content, serum vitamin D metabolite concentrations and ultraviolet-B light exposure in human milk-fed infants with and without vitamin D2 supplements. J Pediatr 1989; 114: 204-212.

9. Hochberg Z. Rickets: it's not just vitamin D deficiency. Curr Opinion Endocrinol Diabetes 2001; 8: 23-8.

10. Walker AR. Etiology of nutricional rickets: geographic variations. J Pediatr 1998; 132: 187-189.

11. Awumey EM, Mitra DA, Hollis BW, Kumar R, Bell NH. Vitamin D metabolism is altered in Asian Indians in the southern United Sates: A Clinical research center study. J Clin Endocrinol Metab 1998; 86: 169-73.
12. Lorentzon M, Lorentzon R, Nordstrom P. Vitamin D receptor gene polymorphism is related to bone density, circulating osteocalcin, and parathyroid hormone in healthy adolescent girls. J Bone Miner Metab 2001; 19: 302-7.

13. Wilss MR, Phillips JB, Day RC, Bateman EC. Phytic acid and nutricional rickets in immigrants. Lancet 1972; 1: 771-3.

14. Thacher TD, Fischer PR, Pettifor JM, Lawson JO, Isichei CO, Reading JC, Chan GM. A comparison of calcium, vitamin D, or both for nutritional rickets in Nigerian children. N Engl J Med 1999; 341: 563-568.

15. López Segura N, Bonet Alcaina M, García Algar O. Raquitismo carencial en inmigrantes asiáticos. An Esp Pediatr 2002; 57: 227-30.

16. Hochberg Z, Bereket A, Davenport M, Delemarre-Van de Waal HA, De Schepper J, Levine MA et al Consensus development for the supplementation of vitamin D in childhood and adolescente Horm Res 2002; 58: $39-51$.

17. Gartner LM, Greer FR. Prevention of Rickets and vitamin D deficiency: new guidelines for vitamin D intake. Pediatrics 2003; 111: 908-910.

18. Park EA. The therapy of rickets. JAMA 1940; 115 : 370-9.

19. Manuel Enguidanos M J. Dosificación de suplementos vitamínico en lactantes. ¿Sabemos lo que damos?. Rev Pediatría de Atención Primaria 1999; 1: 69-73.

20. Adams JS, Lee G. Gains in bone mineral density with resolution of vitamin D intoxication. Ann Intern Med 1997; 127: 203-6.

21. Committe on nutrition, American Academ of Pediatrics en Kleimman RE (ed): Pediatric Nutrition Handbook, 4th ed, Elk Grove Village, Il, American Academy of Pediatrics 1998, pag 631-632; 657-658.

22. Gillespi WJ, Avenell A, Henry DA, D’Oconnell DL, Robertson J. Vitamin D and Vitamin D analogues in the prevention of fracture in involutional and postmenopausal osteoporosis. The Cochrane Library issue 2 , 2001. Oxford: update software. 